
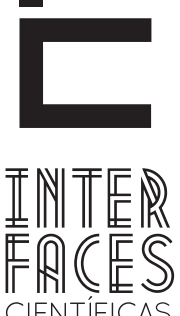

CIENTÍFICAS

HUMANASE SOCIAIS

ISSN IMPRESSO 2316-3348

E-ISSN 2316-3801

DOI - 10.17564/2316-3801.2018v6n3p101-110

\title{
O JUIZZO DE ADOLESCENTES QUANTO A POSSIBILIDADE DE AMAR PESSOA DO SEXO OPOSTO E DO MESMO SEXO ${ }^{1}$
}

\author{
THE JUDGMENT OF TEENAGERS ON THE POSSIBILITY OF LOVING SOMEONE OF THE OPPOSITE SEX AND SAME SEX \\ LA OPINIÓN DE LOS ADOLECENTES CON RELACIÓN A LA POSIBILIDAD DE AMAR UNA PERSONA DEL \\ MISMO SEXO O DEL SEXO OPUESTO.
}

Heloisa Moulin de Alencar ${ }^{3}$

Antonio Carlos Ortega ${ }^{4}$

\section{RESUMO}

O objetivo desta pesquisa foi investigar o conceito que os adolescentes têm sobre o amor, analisando o juízo deles quanto à possibilidade de amar pessoa do sexo oposto e do mesmo sexo, considerando a reflexão sobre a relação da virtude do amor e a moral. Participaram 40 adolescentes de 12 e 15 anos, alunos de escolas particulares de ensino fundamental e médio, igualmente divididos quanto ao sexo e a idade. As entrevistas foram feitas individualmente, com base no método clínico proposto por Piaget. Verificamos que quase a totalidade dos participantes confirmou a possibilidade de amar em ambas as situações, demonstrando uma tendência de não haver influência do sexo da pessoa a ser amada. Os participantes, especialmente de
12 anos, justificaram pela liberdade de escolha em amar, pela experiência vivida por outros e pela experiência própria. Por sua vez, os adolescentes de 15 anos afirmaram a presença de um possível vínculo, ou especificaram a amizade. Destacamos, portanto, a relevância da virtude do amor frente ao desenvolvimento moral, ressaltando a importância das experiências próprias ou as vividas por outros e a possível influência do vínculo no juízo acerca da possibilidade de amar.

\section{PALAVRAS-CHAVE}

Desenvolvimento Moral. Virtudes. Amor. Adolescentes. 


\section{ABSTRACT}

The objective of this research was to investigate the adolescents' concept of love, analyzing their judgment as to whether to love someone of the opposite sex and the same sex, considering the reflection on the relationship of the virtue of love and morality. Participants were 40 adolescents (12 and 15 years old), primary and secondary students' of private schools, divided equally as regard the sex and age. The interviews were conducted individually, based on the clinical method proposed by Piaget. We found that almost all the participants confirmed the possibility of love in both situations, demonstrating a tendency to be no influence of the sex of the person to be loved. Participants, especially adolescents of 12 years old, justi- fied by the freedom of choice in love, the experience lived by others and by their own experience. In turn, adolescents of 15 years old affirmed the presence of a possible bond, or specify friendship. We stress, therefore, the importance of the virtue of love face to the moral development, emphasizing the importance of own experiences or experienced by others and the possible influence of the bond in the judgment of the possibility of love.

\section{KEYWORDS}

Moral development. Virtues. Love. Adolescents.

\section{RESUMEN}

El objetivo de esta pesquisa fue investigar el concepto que los adolescentes tienen sobre el amor, analizando su opinión con relación a la posibilidad de amar a una persona del sexo opuesto o del mismo sexo, partiendo de una reflexión entre la virtud del amor y la moral. Participaron cuarenta alumnos de 12 y 15 años, todos de escuelas privadas de enseñanza primaria y secundaria, igualmente divididos por sexo y edad. Las encuestas fueron hechas individualmente, en base al método clínico propuesto por Piaget. Pudimos observar que todos los entrevistados confirmaran la posibilidad de amar en las dos situaciones, demostrando que no existe influencia del género de la persona que se elige amar. Los participantes, especialmente, los de doce años, justificaron su opinión en base a la libertad de escoger a quien amar, por la experiencia ajena y por su propia. Por su vez, los adolescentes de 15 años, afirmaron la existencia de un vínculo posible o especificaron la amistad. Destacamos, por tanto, la importancia de la virtud del amor ante al desarrollo moral, teniendo en cuenta la importancia de sus propias experiencias o la de los otros y la posible influencia del vínculo al opinar sobre la posibilidad de amor.

\section{PALABRAS-CLAVE}

Desarrollo moral. Virtudes. Amor. Adolecentes. 


\section{INTRODUÇ̃̃O}

Buscamos investigar, partindo da reflexão acerca da relação da virtude do amor com a moral, qual o conceito que os adolescentes têm sobre o amor, analisando o juízo quanto à possibilidade de amar pessoa do sexo oposto e do mesmo sexo. Para isso iniciaremos apresentando a relevância do tema amor em relação ao desenvolvimento moral.

Piaget (1994) estuda o desenvolvimento moral da criança e afirma que até aproximadamente os quatro anos de idade a criança ainda não percebe as normas e regras como obrigatórias, nem as considera associadas ao certo ou errado. Somente mais tarde a criança adentra o mundo da moral (fase nomeada por Piaget de heteronomia), considerando as regras como exteriores ao indivíduo e aceitando como correta o que fora imposto pela figura de autoridade. Há o predomínio do respeito unilateral e as reações de coação, sendo que a criança respeita as normas por medo e amor à figura de autoridade.

Com a interação com outras crianças, pode-se estabelecer relações de cooperação e de respeito mútuo, possibilitando o desenvolvimento da autonomia. Isso permite à criança agir por princípios de reciprocidade e igualdade, passando a compreender as regras, não mais considerá-las exteriores a ela e por isso imutáveis. Assim, a criança tem a possibilidade de fazer suas próprias avaliações morais.

Verificamos que o amor aparece na teoria piagetiana relacionado ao respeito às regras na fase de heteronomia. Seguindo a mesma reflexão, La Taille (2009) destaca que o medo e o amor são indissociáveis para o sentimento de obrigatoriedade necessário para ação moral. Piaget (1994) afirma também que o amor se relaciona a equidade (forma mais refinada de justiça) na fase de autonomia. Assim, analisamos pela teoria de Piaget a relevância da virtude do amor para o desenvolvimento moral.

Acerca das virtudes, La Taille (2000) destaca que todas são merecedoras de estudos psicológicos, uma vez que definir virtude remete-nos à qualidade das pessoas (ou qualidades desejadas), um juízo de valor, ou seja, a representação de si. Assim, fazer uma análise de suas virtudes (ou do que deseja como virtude) possibilita uma leitura valorativa de si próprio e dos outros, relacionando-se ao valor desejável e admirável. La Taille (2000) destaca a importância de se estudar as virtudes altruístas (ou pró-sociais) como a generosidade e a gratidão e também a compaixão, a fidelidade, o amor, entre outras.

Apresentaremos, tendo em vista o objetivo de nosso trabalho, algumas discussões sobre o amor. Comte-Sponville (1999) considera que o amor não pode ser um dever, assim, ele não está presente em uma ação por dever, uma vez que não podemos ordenar que alguém ame o outro ou ame algo. Para ele nós só precisamos de normas e regras porque não temos um amor pleno. Se amássemos verdadeiramente a todos, não necessitaríamos de moral para nos dizer o que deve ser feito, faríamos por amor. Mas na ausência desse amor ideal, recorremos a moral.

Comte-Sponville (1999) considera que somos capazes de agir de forma moral devido ao amor que temos, que nos foi dado, mas não especifica quem nos daria esse amor. Por sua vez, Keleman (1996) destaca que é na família que aprendemos ou não o que é o amor. Mas isso não quer dizer que apenas reproduzimos a forma de amar aprendida na família, mas elaboramos nosso próprio modo a partir dessa experiência.

Ademais, o que é o amor? Para essa definição Comte-Sponville $(1999,2011)$ descreve eros, philia e ágape. Assim eros relaciona-se a paixão amorosa, caracterizado pelo desejo do que falta, sofrimento e carência. Já philia é o amor da amizade, é desejar o bem de seus amigos, é ação. No entanto não é totalmente desinteressada como é o amor ágape, este é o amor universal e gratuito, é a caridade. É renunciar seu prazer em função do amor ao outro.

Por sua vez, Bauman (2004) não considera o amor como renúncia, uma vez que não investiríamos em uma relação amorosa de forma despretensiosa, mas contando com o retorno que podemos ter, seja a sensação de segurança por estar com alguém, ou a certeza de apoio quando precisarmos. Com isso ele 
considera a existência da fragilidade dos vínculos humanos, tendo em vista que o relacionamento seria um investimento como qualquer outro, podendo ser comparado ao mercado de ações: os acionistas têm que estar sempre atentos para saber quando é momento de permanecer com as ações ou se desfazer delas.

A partir destas discussões, vejamos algumas pesquisas sobre o amor. Alves, Alencar e Ortega (2013) entrevistaram crianças de seis e nove anos acerca da possibilidade de amar ou não outra pessoa do sexo oposto como também do mesmo sexo. Seus resultados demonstraram que $85 \%$ dos participantes afirmaram a possibilidade de amar outra criança do sexo oposto, tendo como principal argumento a observação da experiência vivenciada (47\%). Destacaram-se ainda as características da pessoa a ser amada $(13,7 \%)$ e a presença de algum vínculo estabelecido $(11,8 \%)$. Por sua vez, os entrevistados que negaram a possibilidade, principalmente os mais novos, destacaram o fato de ainda serem crianças $(11,8 \%)$, impossibilitando amar outrem.

Acerca da possibilidade de amar uma criança do mesmo sexo, $65 \%$ dos participantes disseram afirmativamente, $27,5 \%$ que não seria possível e 7,5\% falaram que "depende", diferenciando o amor à família e aos amigos do relacionamento amoroso. Sendo que com o aumento da faixa etária elevou-se o número de crianças as quais optaram pela possibilidade de amar outra criança do mesmo sexo. 0 argumento mais citado foi a respeito do relacionamento de amizade e/ou familiar. Foi ressaltada também a experiência vivenciada. Destacamos que a homossexualidade foi proferida como explicação para a impossibilidade de amar (ALVES; ALENCAR; ORTEGA, 2013).

Em outro estudo de Alves, Alencar e Ortega (2014), foi verificada a relevância do vínculo frente à possibilidade de amar em crianças, uma vez que a maior parte dos entrevistados confirmou o amor para com um amigo $(n=35,87,5 \%)$, poucas crianças afirmaram a possibilidade da relação de amor para com o inimigo e $(n=15,37,5 \%)$, menos ainda, para com o desconhecido ( $n=11,27,5 \%)$. Assim, mais difícil do que amar um inimigo é amar aquele que não se tem um vínculo
(ALVES; ALENCAR; ORTEGA, 2014). A importância do vínculo para o conceito de amor também foi verificada nas pesquisas de Souza e Ramires (2006), Costa e Fernandes (2012), tendo em vista que seus participantes descreveram o amor voltado a família e amigos, destacando a importância dessa relação.

Por fim, Ferreira (2010) analisou como o conceito de amor é apresentado pela mídia impressa aos jovens, a partir de análise de revistas destinadas a jovens leitoras, publicadas nos meses de maio e junho de 2009. Verificou-se a menção de que o outro é um adversário, alguém que deve ser combatido e que precisa ser derrotado para que possamos alcançar a vitória e a sensação de felicidade e bem-estar e também a ideia do amor enquanto uma ilusão, ou um negócio. Com isso, Ferreira (2010) destaca a importância da mídia na orientação das ações e formas de pensar das pessoas, refletindo os anseios da sociedade.

Buscamos investigar, tendo em vista as discussões apresentadas, destacando a relevância do amor no desenvolvimento moral, o juízo de adolescentes quanto à possibilidade de amar pessoa do sexo oposto e do mesmo sexo.

\section{MÉTODO}

Participaram desta pesquisa 40 adolescentes com 12 e 15 anos, alunos de escolas particulares de ensino fundamental e médio da Grande Vitória-ES, igualmente divididos quanto à idade e ao sexo. As entrevistas foram feitas individualmente, com base no método clínico proposto por Piaget $(1994,2005)$. Para alcançar os objetivos deste trabalho, perguntamos se o participante considera possível uma pessoa de sua idade amar um adolescente do sexo oposto e amar adolescente do mesmo sexo. Investigamos também as justificativas para as respostas proferidas.

A coleta de dados foi feita em local escolhido pelo participante, desde que o espaço garantisse o sigilo da entrevista. Desse modo, algumas entrevistas foram feitas na própria casa do adolescente como também dentro da instituição escolar. Destacamos que a pesquisa 
seguiu os padrões éticos da Resolução 466/2012 do Conselho Nacional de Saúde (BRASIL, 2012) e que o trabalho foi aprovado pelo Comitê de Ética em Pesquisa do Centro de Ciências Humanas e Naturais (CEP/CCHN).

Além disso, para as entrevistas realizadas dentro da escola, foi encaminhado um termo de consentimento para a instituição, pedindo a autorização para a realização da coleta de dados. Ainda, os pais ou representantes legais dos adolescentes assinaram um temo de consentimento para participação do adolescente na pesquisa e os próprios adolescentes assinaram um termo de assentimento.

Quanto à análise de dados, esta foi realizada com base na teoria piagetiana e sistematização proposta por Delval (2002). Assim, a partir dos protocolos de entrevistas, elaboramos categorias detalhadas das respostas e justificativas mencionadas pelos participantes, para então agrupá-las em categorias resumidas, possibilitando a análise dos dados por pergunta do instrumento. Priorizamos assim a análise qualitativa e utilizamos referências quantitativas em números e percentuais para melhor apresentação e discussão dos resultados.

\section{RESULTADOS E DISCUSSÃO}

Para apresentação dos resultados e das discussões deste estudo, seguiremos o encadeamento da discussão e não a ordem de frequência das categorias. Destacamos que apenas mencionaremos as diferenças nas respostas e/ou nas justificativas em comparação com a idade dos participantes, quando estas forem relevantes.

Perguntamos, então, aos entrevistados se eles consideravam possível amar outro adolescente do sexo oposto. A maioria dos participantes $(n=36$, 90\%) confirmou a possibilidade. Chama-nos a atenção que apesar de poucos afirmarem não ser possível ( $n=4,10 \%)$, o número de respostas aumentou com a idade (passando de um adolescente de 12 anos para três de 15 anos). Comparando com o estudo realizado com crianças, a maioria ( $n=34,85 \%)$ também afirmou esta possibilidade (ALVES; ALENCAR; ORTEGA, 2013). Por meio das justificativas apresentadas na Tabela 1, ressaltamos que os participantes puderam mencionar mais de um argumento.

Tabela 1 - Justificativa sobre amar ou não adolescente do sexo oposto

\begin{tabular}{|c|c|c|c|c|c|c|}
\hline \multirow[b]{2}{*}{ Categoria } & \multicolumn{2}{|c|}{12 anos } & \multicolumn{2}{|c|}{15 anos } & \multicolumn{2}{|c|}{ Geral } \\
\hline & No & $\%$ & No & $\%$ & No & $\%$ \\
\hline Ausência de influência da idade & 5 & 17,2 & 6 & 21,4 & 11 & 19,3 \\
\hline Liberdade de escolha em amar & 7 & 24,1 & 3 & 10,7 & 10 & 17,6 \\
\hline Experiência vivenciada por outros & 6 & 20,7 & 4 & 14,3 & 10 & 17,6 \\
\hline Experiência própria & 4 & 13,8 & 2 & 7,2 & 6 & 10,5 \\
\hline Presença de vínculo & 2 & 6,9 & 4 & 14,3 & 6 & 10,5 \\
\hline Falta ou fragilidade de vínculo & 1 & 3,5 & 3 & 10,7 & 4 & 7,0 \\
\hline Característica da pessoa amada & 2 & 6,9 & 0 & 0,0 & 2 & 3,5 \\
\hline Outros & 2 & 6,9 & 6 & 21,4 & 8 & 14,0 \\
\hline TOTAL & 29 & 100,0 & 28 & 100,0 & 57 & 100,0 \\
\hline
\end{tabular}

Fonte: Dados da pesquisa. 
As justificativas para a possibilidade de amar se basearam principalmente na ausência da influência da idade, ou seja, o fato de ser ou não adolescente não traria consequência na possibilidade de amar, como afirma Daiana 5 , "porque eu acho que quando você ama alguém, você ama de verdade. Não tem, sei lá, idade não, não é isso. Amor você sente a partir do momento que você ama. Só isso". Na pesquisa com crianças (ALVES; ALENCAR; ORTEGA, 2013) foi analisada a impossibilidade de amar por ainda ser criança, sendo que essas justificativas diminuíram com a idade. Assim, frente aos nossos dados com adolescentes, a idade da pessoa não seria mais impedimento para a relação amorosa.

Outro argumento foi a liberdade de escolha em amar, assim as pessoas são livres em escolher quem amar, conforme defende Damião: "porque é o livre arbítrio. Você pode amar”. Assim, não haveria qualquer impedimento para existência do amor. De forma semelhante menciona Comte-Sponville (2011) que o amor não corresponde a um dever, não se pode obrigar ninguém a amar, como também não se pode impedi-lo. Assim o amor não pode corresponder a uma obrigação. Assim, de acordo com nossos participantes, temos liberdade (e não obrigação e nem impedimento) de amar outrem. Esta justificativa foi mais frequente nos adolescentes de 12 anos, o que pode estar relacionado com o fato de os participantes de 15 anos terem mencionado outras explicações, como veremos adiante.

Foi explanado, também, acerca da experiência vivenciada por outros, destacando a influência da família ( $n=3)$, amigos ( $n=2)$, mídia $(n=1)$ e escola $(n=1)$, sendo que outros ( $n=3)$ não especificaram a influência. Vejamos a fala de Marly: "porque, como exemplo, a minha mãe se apaixonou pelo meu pai quando ela era mais nova que eu. 13 anos. E eles são casados hoje". A influência da família também é destacada por Keleman (1996), uma vez que ele discute que o modo

5 Para garantir o anonimato, atribuímos nomes fictícios aos participantes, sendo os iniciados com a letra "D" para os de 12 anos, e os nomes iniciados com a letra " $M$ " para os entrevistados de 15 anos. como as pessoas foram amadas por sua família interfere nas suas formas de amar.

Além disso, também seríamos influenciados pela observação de como outras pessoas experienciam o amor, além da visão retirada de jornais, novelas e filmes. Fazendo uma reflexão acerca da influência da mídia, Ferreira (2010) discorre que é inegável sua importância: orienta as ações das pessoas e até a forma de pensar, no entanto, ela própria é o reflexo da sociedade, refletindo seus anseios.

Ainda, outros adolescentes afirmaram pela experiência própria. Nesse sentido discorre Maitê, "porque eu mesma já amei. Porque acontece. E, fora que... não só em questão de namorado, amiga também, amigos, assim... eu amo meus amigos, entendeu?" A experiência foi o principal argumento das crianças ( $n=24,47 \%)$, sendo ela própria ou vivida por outrem (ALVES; ALENCAR; ORTEGA, 2013). Piaget (1994) destaca que é a partir da interação com outras pessoas (ou seja, suas experiências, como por exemplo, a de amor para com seus pares) que podemos estabelecer relações de cooperação e de respeito mútuo e assim desenvolvermos a autonomia moral. Ressaltamos, portanto, a importância das experiências na formulação de seus conceitos.

Verificamos que tanto a experiência vivida por outros quanto a experiência própria foram mais citadas pelos participantes de 12 anos. Este decréscimo em relação à idade pode ser analisado também quando comparamos com o estudo com crianças (ALVES; ALENCAR; ORTEGA, 2013), uma vez que estes argumentos corresponderam a $47 \%$ das justificativas, enquanto que na presente pesquisa com adolescentes $28,1 \%$ (somando-se as duas categorias). Analisamos, portanto, que para os adolescentes outros argumentos tomam destaque como a reflexão sobre a ausência da influência da idade, liberdade em escolher quem amar e a presença do vínculo, como veremos agora.

Por sua vez, a possível presença de vínculo foi outro motivo para a possibilidade de amar. Assim, pode-se amar se "for uma pessoa que você conhece há muito tempo, você já tem uma afinidade com ela, já tem uma amizade muito boa e a pessoa também tem que gostar de você para amar" (DIANA). Esta 
categoria foi mais mencionada pelos participantes de 15 anos, afirmando a importância do vínculo. De modo semelhante podemos verificar no estudo com crianças (ALVES; ALENCAR; ORTEGA, 2013), uma vez que $11,8 \%$ das justificativas consideraram o relacionamento familiar ou de amizade. Além disso, outras pesquisas também demonstram a relação da presença do vínculo com a possibilidade de amor (ALVES; ALENCAR; ORTEGA, 2014; COSTA; FERNANDES, 2012; SOUZA; RAMIRES, 2006).

Ainda, característica da pessoa amada, foi afirmada apenas pelos adolescentes de 12 anos, enfatizando que a pessoa pode ser legal e pode-se gostar das características dela. Também foi mencionada pelas crianças (ALVES; ALENCAR; ORTEGA, 2013), correspondendo a $13,7 \%$ dos argumentos. Vemos, portanto, que para as crianças a característica da pessoa era um aspecto mencionado para a possibilidade de amar e com o desenvolvimento, na adolescência há diminuição desse tipo de explicação.

Podemos fazer uma aproximação das justificativas sobre presença de vínculo e característica da pessoa amada ao amor philia, descrito por Comte-Sponville $(1999,2011)$ como o amor aos amigos, é o amor àqueles que nos estão próximos. Este amor considera a presença de algum vínculo para o estabelecimento da relação amorosa.

Agora, os participantes que defenderam a impossibilidade de amar adolescente do sexo oposto argumentaram principalmente sobre a falta ou fragilidade de vínculo, como podemos observar na fala de Miriam:

Porque, hoje em dia, todo mundo só pensa em sexo, droga, orgia, sair, curtir, ficar com a menina e depois meter o pé na bunda dela, literalmente. E... são poucos que querem alguma coisa séria. Alguma coisa de verdade. E eu acho que os meninos que... ainda tinha essa chance de querer alguma coisa, já estão perdendo. Por causa que as meninas não estão dando valor a si próprias. Fica tirando foto pelada e essas coisas todas desnecessárias. Que eu não aceito, eu acho isso um absurdo. [...] Hoje fala que ama, amanhã odeia.

Estas ideias nos remetem ao defendido por Bauman (2004) acerca de vivermos uma modernidade líquida e com isso à fragilidade dos laços humanos, um amor líquido. Este argumento foi mais mencionado pelos adolescentes de 15 anos, demonstrando a importância do vínculo e a reflexão feita por eles, considerando nosso momento atual.

Em outros incluímos as seguintes justificativas para a possibilidade de amar adolescente de sexo oposto: sobre a consequência positiva, ser possível amar diversas pessoas, reciprocidade, relacionamento amoroso, possibilidade de andar de mãos dadas, confusão dos sentimentos devido aos hormônios. Além disso, acrescentamos os argumentos para a impossibilidade de amar adolescente de sexo oposto: diferença do amor aos pais e presença da influência da idade.

Verificamos, portanto, que os adolescentes de 15 anos destacam a condição do vínculo, uma vez que enfatizam a possibilidade de amar outrem pela presença do vínculo e a impossibilidade de amar pela sua falta ou fragilidade. Por sua vez, os participantes mais novos utilizam-se de argumentos mais concretos como a característica da pessoa a ser amada e o fato de ocorrer uma experiência, além de reflexões centradas neles mesmos, como a liberdade que eles têm de escolher quem amar.

Quando questionamos sobre a possibilidade de amar outro adolescente do mesmo sexo, a maioria $(n=35,87,5 \%)$ também afirmou ser possível. Apenas cinco adolescentes (12,5\%) negaram a possibilidade, sendo dois de 12 anos e três de 15 anos. Ressaltamos que destes, quatro também haviam rejeitado o amor entre adolescentes do sexo oposto. Assim, parece não ter havido influência se a pessoa era do sexo oposto ou do mesmo sexo na escolha em amar.

Um número maior de entrevistados, comparando com o estudo com crianças (ALVES; ALENCAR; ORTEGA, 2013), negou a possibilidade de amor a outra criança do mesmo sexo ( $n=11,27,5 \%)$, sendo oito de seis anos e três de nove anos. Portanto, este tipo de resposta diminuiu com a idade, podendo ter relação com a baixa frequência dessa categoria quando pesquisamos adolescentes. Vejamos agora os argumentos assinalados na Tabela 2. 
Tabela 2 - Justificativa sobre amar ou não adolescente do mesmo sexo

\begin{tabular}{|c|c|c|c|c|c|c|}
\hline \multirow[b]{2}{*}{ Categoria } & \multicolumn{2}{|c|}{12 anos } & \multicolumn{2}{|c|}{15 anos } & \multicolumn{2}{|c|}{ Geral } \\
\hline & No & $\%$ & No & $\%$ & No & $\%$ \\
\hline Experiência vivenciada por outros & 10 & 34,5 & 6 & 18,8 & 16 & 26,2 \\
\hline Liberdade de escolha em amar & 8 & 27,6 & 5 & 15,6 & 13 & 21,3 \\
\hline Amizade & 2 & 6,9 & 8 & 25,0 & 10 & 16,4 \\
\hline Homossexualidade & 2 & 6,9 & 3 & 9,4 & 5 & 8,2 \\
\hline Ausência de diferença quanto ao sexo & 0 & 0,0 & 4 & 12,5 & 4 & 6,6 \\
\hline Amor a familiares & 2 & 6,9 & 1 & 3,1 & 3 & 4,9 \\
\hline Outros & 5 & 17,2 & 5 & 15,6 & 10 & 16,4 \\
\hline TOTAL & 29 & 100,0 & 32 & 100,0 & 61 & 100,0 \\
\hline
\end{tabular}

Fonte: Dados da pesquisa.

Para justificar a possibilidade de amar outro adolescente do mesmo sexo também foi mencionada a experiência vivenciada por outros, sendo especificada por alguns a influência da família $(n=3)$, da amizade $(n=2)$ e da mídia $(n=1)$; outros $(n=7)$ apenas falaram que já haviam visto ou conheciam alguém que amava outra pessoa do mesmo sexo e ainda afirmaram $(n=3)$ ser muito frequente nos dias atuais. A Maria destaca a influência da família: "O meu tio é gay e eu acho que isso é super bonito. Ele vive junto com o namorado dele e ponto". Vejamos que quando perguntamos sobre a possibilidade de amar alguém do sexo oposto houve menção tanto à experiência própria, quanto àquela vivenciada por outro. Aqui, com pessoas do mesmo sexo, as justificativas basearam-se apenas nas experiências de outros.

Embora tenha sido citada com maior frequência pelos participantes de 12 anos, quando comparado com o estudo com crianças (ALVES; ALENCAR; ORTEGA, 2013) vemos um aumento desse argumento no presente estudo, uma vez que essa categoria correspondeu a apenas $5,1 \%$ das justificativas na pesquisa realizada em 2013.

Em seguida foi citada a liberdade de escolha em amar, afirmando que "não tem nada escrito assim 'ah, você não pode fazer isso'. A pessoa é livre, você que pode escolher quem você vai amar, quem você gosta" (DANIEL). Esta categoria também foi justificativa para a possibilidade de amar adolescente do sexo oposto e foi proferida com maior frequência pelos participantes de 12 anos.

Foi mencionada também a amizade como possibilidade de amor, além do amor aos familiares, sendo que os adolescentes de 15 anos enfatizaram a amizade. Somando as categorias amor aos familiares e amizade, vemos que $21,3 \%(n=13)$ dos argumentos salientaram o vínculo. Essas justificativas se aproximam ao afirmado anteriormente (na possibilidade de amar adolescente do sexo oposto) sobre a presença de vínculo, fazendo um destaque ao amor philia, que é 
o amor que temos aos que estão próximos e queremos o bem (COMTE-SPONVILLE, 1999, 2011).

De forma semelhante, no estudo com crianças acerca da possibilidade de amar uma pessoa do mesmo sexo, declarações sobre amar devido à possibilidade de amizade e de haver um relacionamento familiar corresponderam a 42,4\% do total de argumentos ( $A L-$ VES; ALENCAR; ORTEGA, 2013). Tanto no referido estudo com crianças como na pesquisa atual com adolescentes, a frequência dos argumentos em relação à amizade aumentou com a idade.

Por sua vez, apenas os de 15 anos defenderam a ausência de diferença quanto ao sexo. Assim, é possível amar pessoa do mesmo sexo, pois não seria diferente quanto amar alguém do sexo oposto. Como diz Manuela, “assim como um tem atração pelo sexo oposto, ela pode ter atração pelo mesmo sexo. Eu vejo como a mesma coisa”.

Foi citada também a homossexualidade, tanto como argumento para a possibilidade de amar $(n=3)$ quanto para a impossibilidade de amar $(n=2)$. Podemos aproximar esta explicação ao amor eros, correspondente à paixão amorosa (COMTE-SPONVILLE, 1999, 2011). No estudo com crianças (ALVES; ALENCAR; ORTEGA, 2013) essa foi citada apenas para a impossibilidade de amar $(n=2,3,4 \%)$. Vemos, assim, que os adolescentes passam a compreender a homossexualidade como possibilidade de amor.

E em outros, agrupamos justificativas sobre sentimento $(n=1)$, confiança $(n=1)$, convivência $(n=1)$ e ausência da influência da idade $(n=1)$, explicando a possibilidade de amar. Por sua vez, os argumentos sobre a fragilidade de vínculo $(n=2)$, presença da influência da idade $(n=1)$, falta de experiência $(n=1)$, o fato de não darem a vida por outra pessoa $(n=1)$ e de enjoarem de ter namorado pela imposição da mãe $(n=1)$ justificam a impossibilidade de amar.

\section{CONSIDERACOÕES FINAIS}

Quando comparamos as respostas acerca da possibilidade de amar adolescente de sexo oposto (90\%) e de mesmo sexo $(87,5 \%)$ parece não haver influência se a pessoa era do sexo oposto ou do mesmo sexo na escolha em amar. Inclusive alguns entrevistados argumentaram acerca da ausência de diferença quanto ao sexo $(n=4,6,6 \%)$ para ressaltar este fato.

No entanto, no que diz respeito às justificativas das referidas respostas, destacamos que foi mencionada a experiência própria e vivida por outro para argumentar a possibilidade de amar adolescente do sexo oposto, enquanto que para a possibilidade referente ao mesmo sexo, foi citada apenas a experiência de outros, não sendo declarada a experiência própria. Estas explicações foram citadas especialmente por participantes de 12 anos, juntamente com os argumentos sobre a liberdade de poder escolher quem amar (justificativas proferidas nas duas situações mencionadas anteriormente).

Assim, enquanto os entrevistados mais novos argumentaram acerca das experiências e da liberdade, os mais velhos destacam o vínculo. Nesse sentido, as explicações para amar pessoa do sexo oposto seriam pela presença de vínculo e a impossibilidade de amar pela fragilidade desse vínculo; e em relação à pessoa do mesmo sexo seria possível amar devido à amizade. Com isso, constatamos a relação do vínculo na possibilidade de amar para nossos entrevistados, especialmente pelos de 15 anos.

A partir do apresentado neste trabalho, destacamos a relevância da virtude do amor frente ao desenvolvimento moral, ressaltando a importância das experiências e a possível influência do vínculo na possibilidade de amar. Esperamos que o nosso trabalho possa contribuir para o desenvolvimento de novas pesquisas sobre o tema e propostas de intervenção. 


\section{REFERÊNCIAS}

ALVES, A.D.; ALENCAR, H.M., ORTEGA, A.C.

Possibilidade de amar menino e menina: um estudo sob a ótica de crianças. Revista de Psicologia,

Fortaleza, v.4, n.1, p.26-37, 2013.

ALVES, A.D.; ALENCAR, H.M., ORTEGA, A.C. O juízo de crianças sobre a possibilidade de amar um amigo, um inimigo e um desconhecido. Psicologia em Revista, Belo Horizonte, v.20, n.3, p.529-548, 2014.

BAUMAN, Z. Amor líquido: sobre a fragilidade dos laços humanos. Rio de Janeiro: Jorge Zahar, 2004.

BRASIL. Conselho Nacional de Saúde. Resolução n⿳0 466, de 12 de dezembro de 2012. Brasília, 2012.

COMTE-SPONVILLE, A. Pequeno tratado das grandes virtudes. São Paulo: Martins Fontes, 1999.

COMTE-SPONVILLE, A. 0 amor. São Paulo: Martins Fontes, 2011.

COSTA, V., FERNANDES, S. O que pensam os adolescentes sobre o amor e o sexo? Um estudo na perspectiva das representações sociais. Psicologia \& Sociedade, v.24, n.2, p.391-401, 2012.
DELVAL, J. Introdução à prática do método clínico: descobrindo o pensamento das crianças. Porto Alegre: Artmed, 2002.

FERREIRA, A.P. As metáforas do amor em revistas para adolescentes. Cadernos do CNLF, v.15, n.2, 2010.

\section{KELEMAN, S. Amor e vínculos. Uma visão}

somático-emocional. São Paulo: Summus, 1996.

LA TAILLE, Y. Para um estudo psicológico das virtudes morais. Educação e Pesquisa, v.26, n.1, p.109-121, 2000.

LA TAILLE, Y. Formação ética: do tédio ao respeito de si. Porto Alegre: Artmed, 2009.

PIAGET, J. 0 juízo moral na criança. 2.ed. São Paulo: Summus, 1994.

PIAGET, J. Introdução - Problemas e métodos. In: A representação do mundo na criança. Aparecida-SP: Idéias e Letras, 2005. p.9-31.

SOUZA, R.M. de; RAMIRES, V.R.R. Amor, casamento, família, divórcio... e depois, segundo as crianças.

São Paulo: Summus, 2006. 